\title{
Complex cancer pain - when intrathecal analgesia is not enough
}

\author{
Woong Liling Natalie* \\ Department of Internal Medicine, Singapore General Hospital, Singapore
}

\begin{abstract}
Complex pain in advanced cancer is a challenging entity to treat. Interventional strategies such as intrathecal analgesia is utilised when conventional systemic therapy is ineffective. However, in some cases even interventional management does not achieve good outcomes. This report aims to explore the barriers to effective pain control and different strategies of pain management in a patient with Stage IV Diffuse Large B-Cell Lymphoma and complex pain from extensive bone metastases.
\end{abstract}

\section{Introduction}

Pain is a distressing symptom that affects about $66 \%$ of patients with advanced cancer. Among these, 51.9\% have moderate to severe pain [1]. Approximately $75-90 \%$ of patients with cancer related pain syndromes achieve symptom control with treatment guided by the World Health Organisation (WHO) Pain Relief [2]. However this means that $10-20 \%$ of patients do not achieve satisfactory pain control [3]. Patients with complex pain require more time to achieve stable pain control and may require different interventions [4] including intrathecal analgesia.

\section{Case report}

ABN was a 65-year-old Malay woman with Stage 4 Diffuse Large B-Cell Lymphoma (DLBCL) with complex pain from extensive bone metastases.

\section{Oncological history}

She was diagnosed with Stage 4 DLBCL in July 2013. She completed chemotherapy in November 2013 then relapsed in September 2016 with multiple bone metastases in the axial and appendicular skeleton. There were pathological fractures in the left sacral ala and right L5 transverse process. She underwent chemotherapy from September to November 2016 and a PET scan on 19 December 2016 showed good response.

Before her next cycle of chemotherapy, she was admitted in February 2017 for left hip pain and a computed tomography (CT) scan of her thorax, abdomen and pelvis showed disease progression in the left sacral ala with bilateral sacral insufficiency fractures. A family conference was held by her oncologist on 7 February and best supportive care recommended due to disease relapse soon after chemotherapy and declining function. She was seen by radiation oncology and received 4 fractions of radiotherapy (RT) for her left hip and pelvis region from 9 to 13 February. CT of her abdomen and pelvis on 11 April showed larger left para-aortic lymphadenopathy and stable left sacral ala lytic lesion with smaller soft tissue component in the left second sacral foramen. The bilateral sacral ala insufficiency fractures, L5 transverse process fracture and left inferior pubic ramus fracture were healing with callus formation.

\section{Past medical history}

ABN had a history of diabetes mellitus, hypertension, stage 3 chronic kidney disease and left breast cancer in 2001 which had been treated with surgery, adjuvant chemoradiotherapy and 5 years of tamoxifen.

\section{Previous input from palliative care}

She had three hospitalisations for left hip and lower back pain and her treatment is summarized below (Table 1).

\section{History of presenting complaint}

She presented on 26 April with recurrence of her lower back pain. She had dull pain with numbness that radiated to both lower limbs down to the sole of the foot, particularly the left, and occasional electric shock sensations. Baseline pain score was 4 with intermittent increases to 8 and worse on walking and turning. She was taking an average of 4 breakthrough oxynorm doses a day and complained of constipation, nausea and occasional vomiting. Her maid was unable to cope with her care needs.

\section{Physical examination}

On physical examination, she had weakness of her left hip and knee flexion and extension. Bilateral knee jerks were depressed, and ankle jerks were absent. There was no spinal tenderness, numbness or allodynia. Anal tone was normal.

\section{Investigations}

$\mathrm{X}$-rays of her lumbar spine and sacrum on 1 May showed lumbar spondylosis, cortical irregularity at $\mathrm{S} 5$ and mild ventral subluxation of the second piece of the coccyx.

${ }^{\star}$ Correspondence to: Woong Liling Natalie, Associate Consultant, Department of Internal Medicine, Singapore General Hospital. Email: natalie.woong.1.1@ singhealth.com.sg

Received: July 17, 2019; Accepted: July 23, 2019; Published: July 26, 2019 
Table 1. Treatment history

\begin{tabular}{|l|l|}
\hline Date & Medications \\
\hline 12 September - 5 October 2016 & Transdermal (TD) fentanyl 37mcg/hr, oxynorm 5mg Q2H PRN, gabapentin 300mg thrice daily (TDS) \\
\hline 31 January - 13 February 2017 & $\begin{array}{l}\text { 5-9 February: Ketamine (Burst protocol 4mg/hr } \rightarrow 8 \mathrm{mg} / \mathrm{hr} \rightarrow 12 \mathrm{mg} / \mathrm{hr}) \\
\text { 9-13 February: RT to left hip and pelvis 20 Gy/4 fractions } \\
\text { Oxynorm 10mg Q4H and Q1H PRN, nortriptyline 35mg at night (ON), gabapentin 400mg TDS }\end{array}$ \\
\hline February - April 2017 & $\begin{array}{l}\text { Medications titrated by home hospice to TD fentanyl 87mcg/hr, gabapentin 600mg TDS, oxynorm 10mg Q1H PRN* } \\
\text { *Breakthrough dose kept at 10mg due to myoclonic jerks }\end{array}$ \\
\hline 9 - 20 April 2017 & TD fentanyl 125mcg/hr, oxynorm 15mg Q1H PRN, gabapentin 600/300/600mg, dexamethasone (tapering dose) \\
\hline
\end{tabular}

\section{Psychosocial}

ABN was a divorcee with 4 adult children. She was aware of her diagnosis and hoped for a peaceful and pain-free death as she had seen her late husband suffer in his last moments. ABN was actively supported by the medical social worker (MSW) for financial concerns and family conflicts. She coped through avoidance by distracting herself with the television or radio. She previously had a distant relationship with her son but they had reconciled prior to this admission.

\section{Issues and progress during current admission}

\section{Titration and escalation of medications}

She had generalized pain and oxynorm breakthroughs caused myoclonic jerks and drowsiness. A fentanyl infusion of $35 \mathrm{mcg} / \mathrm{hr}$ was started in addition to her transdermal fentanyl $125 \mathrm{mcg} / \mathrm{hr}$ with breakthrough doses of $100 \mathrm{mcg}$. While her pain initially improved, she developed drowsiness, giddiness and slurred speech on 3 May due to worsening renal function and possible accumulation of gabapentin. Gabapentin was stopped, transdermal fentanyl was removed, and fentanyl infusion adjusted to $75 \mathrm{mcg} / \mathrm{hr}$ then uptitrated to $100 \mathrm{mcg} / \mathrm{hr}$ on 6 May due to worsening pain.

\section{Opioid rotation to methadone}

She was opioid rotated to methadone as she was still requiring 2 to 3 hourly breakthroughs. Her target methadone dose was $25 \mathrm{mg} /$ day based on a fentanyl dose of $150 \mathrm{mcg} / \mathrm{hr}$ and a $30 \%$ reduction. Her opioid rotation schedule was:

7 May: Methadone $2.5 \mathrm{mg}$ TDS, fentanyl infusion $100 \mathrm{mcg} / \mathrm{hr}$, IV fentanyl 150mcg Q1H PRN

8 May: Methadone 5mg TDS, fentanyl infusion $50 \mathrm{mcg} / \mathrm{hr}$, IV fentanyl 150mcg Q1H PRN

9 May: Methadone 7.5mg TDS, fentanyl infusion stopped, mist morphine 10mg Q2H PRN

Her pain was initially well controlled on Methadone 7.5mg TDS but on 14 May her left leg pain recurred and she required multiple breakthrough doses of morphine. She was switched back to fentanyl breakthroughs due to worsening renal function. She had one dose of pregabalin $75 \mathrm{mg}$ but that was stopped due to drowsiness. Her methadone dose was further increased to $10 \mathrm{mg} / 7.5 \mathrm{mg} / 10 \mathrm{mg}$ on 16 May however she still required multiple breakthroughs which also caused sedation.

\section{Intrathecal catheter insertion}

In view of her poorly controlled pain and side effects with analgesia, a referral was made to the Chronic Pain team for intrathecal analgesia. Prior to IT catheter insertion, she was on Methadone $7.5 \mathrm{mg} / 7.5 \mathrm{mg} / 10 \mathrm{mg}$, fentanyl infusion $20 \mathrm{mcg} / \mathrm{hr}$ and breakthrough fentanyl $120 \mathrm{mcg}$ PRN. Her morphine equivalent daily dose (MEDD) in the 24 hours prior to the procedure was $420 \mathrm{mg}$, including a total of $1420 \mathrm{mcg}$ of fentanyl in breakthrough doses.
She underwent IT catheter insertion on 19 May and was started on an IT infusion of $0.1 \%$ bupivacaine with $0.1 \mathrm{mg} / \mathrm{ml}$ morphine at a rate of $0.5 \mathrm{mls} /$ hour via a continuous ambulatory delivery device (CADD) pump. Bolus doses were set at $0.3 \mathrm{mls}$ with a maximum of 4 doses an hour and a lockout period of 15 minutes. Her methadone dose was reduced to $5 \mathrm{mg} / 5 \mathrm{mg} / 10 \mathrm{mg}$.

Over the first three days after the IT infusion was started, she had multiple attempted boluses and received about 50 IT boluses a day with additional fentanyl breakthroughs. She was given Mirtazapine $7.5 \mathrm{mg}$ ON on 23 May for insomnia and low mood. Her IT morphine dose was increased to $0.2 \mathrm{mg} / \mathrm{ml}$ on 24 May.

She began asking for euthanasia on 24 May and a combined session with a psychiatrist, occupational therapist and MSW was organized. Her mood was labile, and she tended to cry out in pain when approached by healthcare staff. She expressed concerns about her family and also shared that she felt ready for death. However, there was still unresolved conflicts among her children. The MSW's assessment was that $\mathrm{ABN}$ was experiencing inner conflict about letting go of her responsibilities although death was considered to be a release.

On 26 May, she was more comfortable, and the number of IT boluses reduced. However, that evening she developed severe perineal pain following a change of her indwelling urinary catheter and it was removed. She was tachycardic and attempted IT boluses 84 times, with 33 boluses delivered. She became drowsier from a combination of sepsis, anaemia, uraemia and disease progression on 28 May. She was unable to take her oral methadone and her use of breakthrough medication became markedly reduced. She deteriorated rapidly and died on 29 May 2017.

\section{Discussion and focused literature review}

ABN suffered from mixed nociceptive and neuropathic lower back, buttock and bilateral lower limb pain due to progressive DLBCL with L2-3 metastases, L5 transverse process pathological fracture and left inferior pubic ramus fracture. She required escalating doses of opioids with poor analgesic response, opioid rotation to methadone, use of intrathecal analgesia and had significant psychological and emotional distress. In the following section, we will discuss an approach to assessing complex cancer pain and management strategies.

\section{Definition and concepts of complex pain}

Pain is defined as an "unpleasant sensory and emotional experience associated with actual or potential tissue damage, or described in terms of such damage" [5]. In palliative care, the concept of total pain acknowledges the influence of a person's physical, psychological, social, spiritual and practical struggles on the experience of pain and suffering. While there is no consensus on what constitutes complex pain, certain factors are associated with more difficult pain control. Bruera developed the Edmonton Staging System (ESS) for a clinical staging system for cancer pain [6]. A validation study done on the revised ESS 
(rESS) showed that factors associated with a longer time to achieve stable pain control were - younger age (less than 60 years), neuropathic pain, incident pain, psychological distress and addiction. Patients with neuropathic or incident pain required more pharmacological and nonpharmacological modalities to achieve stable pain control. Patients with neuropathic pain, incident pain, psychological distress or addiction also required higher final morphine equivalent daily doses [4].

\section{Classification and prognostication of cancer pain}

The Edmonton Classification System for Cancer Pain (ECS-CP) [7] was evolved from the ESS and developed as a standardized system to discuss cancer pain and predict pain management complexity [4].

Using the ECS-CP, her pain profile is:

(i) $\mathrm{Ne}$ - Neuropathic pain syndrome with or without any combination of nociceptive pain

(ii) Ii - incident pain present

(iii) $\mathrm{Pp}$ - Psychological distress present

(iv) Ao - No addictive behavior

(v) $\mathrm{Cx}$ - Insufficient information of cognitive function

The negative prognostic features that she had were neuropathic pain, presence of incident pain and psychological distress.

\section{Assessment of pain}

Comprehensive assessment of malignant bone pain requires (1) the patient's trust, (2) careful pain history taking, (3) evaluation of the patient's psychological state, (4) neurological examination and (5) reviewing of investigations [8]. An individualized therapeutic approach can then be formulated.

Her pain syndrome can be described as cancer-associated bone pain (CABP) due to bony metastases and skeletal related events (SRE). She had pathological fractures and radiculopathy from spinal metastases. CABP has been described as a combination of background, spontaneous and incident pain [8]. Research on the mechanisms of pain in cancer-colonized bone revealed the neuropathic component of bone pain [9], where changes in bone microenvironment trigger nociceptive sensory neurons.

Psychosocial issues also contributed to her distress. She was concerned about family conflicts, financial issues and place of care. She was sometimes consolable with the presence of her family or healthcare staff. She also faced difficulty in communicating her needs as she was mainly Malay-speaking.

Assessment of ABN's pain and psychological state became challenging as she deteriorated due to delirium, fatigue and drowsiness from progressive disease and medication side effects.

\section{Management}

ABN received multiple therapies for pain control. A stepwise approach to complex pain has been suggested [10]:
1. Primary therapies to address underlying cause of the pain

2. Titration of opioids to maximum tolerated dose

3. Management of side effects with drugs or opioid rotation

4. Consider adjuvant analgesics

5. Consider regional anaesthetic approaches

6. Consider invasive neuroablative interventions

7. Use of sedation for refractory pain at end of life

She was initially started on opioid analgesics and neuropathic adjuvants. She also received ketamine, methadone and eventually intrathecal analgesia. We will discuss the therapy she received with a focus on intrathecal analgesia.

\section{Section 1: Neuropathic agents}

Pharmacotherapy for neuropathic agents were reviewed in a systematic review and meta-analysis and recommended tricyclic antidepressants (TCA), serotonin-noradrenaline reuptake inhibitors (SNRI), pregabalin and gabapentin as first line treatment in neuropathic pain [11].

Study findings for the above medications are summarized in the (Table 2) below.

ABN's pain was initially controlled with opioids and regular gabapentin. Subsequently she received combination nortriptyline and gabapentin. Randomised controlled trials of the addition of morphine to gabapentin [12] and nortriptyline to gabapentin [13] showed that combination therapy led to greater efficacy at lower combined doses than if each drug were used as single agents. However, of note, these studies were done in patients with diabetic neuropathy or postherpetic neuralgia.

\section{Section 2: Methadone in cancer pain}

$\mathrm{ABN}$ was opioid rotated to methadone because of poor response to fentanyl with increasing side effects of sedation and renal impairment (declining urine output). Methadone is a synthetic strong opioid analgesic. It is a $\mu$-opioid receptor agonist with $\delta$-opioid receptor affinity, an N-methyl-D-aspartate (NMDA) antagonist and blocks presynaptic serotonin re-uptake. Its actions on multiple receptors make it an opioid of choice for patients with complex pain syndromes. It has similar analgesic efficacy to morphine [14]. Methadone is indicated when there is neuropathic or mixed nociceptive-neuropathic pain that is poorly responsive to morphine or other $\mu$-receptor agonists [15], development of dose-limiting side effects with opioid use and renal impairment. The main concerns with use of methadone are respiratory depression, QT prolongation and drug interactions with medications metabolized by CYP450. A recent systematic review has suggested that methadone may be considered as a first line drug in the management of cancer pain [16].

ABN initially saw an improvement in her pain with methadone, however that improvement was not sustained and further increases in

Table 2. Comparison of neuropathic agents

\begin{tabular}{|c|c|c|}
\hline Drug Name & Number Needed to Treat (95\% CI) & $\begin{array}{c}\text { Number Needed to Harm } \\
(\mathbf{9 5 \%} \text { CI) }\end{array}$ \\
\hline Tricyclic antidepressants & $3.6(3.0-4.4)$ & $13.4(9.3-24.4)$ \\
\hline Serotonin-noradrenaline reuptake inhibitors & $6.4(5.2-8.4)$ & $11.8(9.5-15.2)$ \\
\hline Pregabalin & $7.7(6.5-9.4)$ & $13.9(11.6-17.4)$ \\
\hline Gabapentin & $6.3(5.0-8.3)$ & $25.6(15.3-78.6)$ \\
\hline
\end{tabular}


analgesia were limited by side effects. Intrathecal analgesia was then discussed.

\section{Section 3: Interventional pain management}

In patients who do not achieve adequate pain relief from standard systematic analgesia or who suffer unacceptable side effects from treatment, interventional pain management is a consideration.

\section{Mechanism of action}

In intrathecal therapy, medications are delivered directly to the spinal fluid, compared with epidural therapy, where medications are delivered along the epidural sac with diffusion into the spinal fluid. Epidural and intrathecal medications target nerve conduction pathways in the spinal cord, leading to analgesia with reduced drug concentrations and diminished systemic toxicities [17].

There are two major advantages of intrathecal therapy. Firstly, the ability to give different classes of drugs for which there is no oral equivalent (Table 3). An example would be the local anaesthetics. Bupivacaine and other lidocaine-type drugs can be used intrathecally.

Secondly, as a result of direct action on opioid receptors in the spinal cord, intrathecal analgesia allows the escalation of drugs with fewer systemic side effects [18]. Conversion ratios of systemic to epidural or intrathecal doses are currently recommended by consensus [19] and the ratios for morphine are shown in Table 4.

In ABN's case, prior to the insertion of IT catheter she was on a MEDD of $420 \mathrm{mg}$. Her IT morphine dose was $0.05 \mathrm{mg} /$ hour with methadone reduced to $5 \mathrm{mg} / 5 \mathrm{mg} / 10 \mathrm{mg}$ (total MEDD $360+200=$ $560 \mathrm{mg}$, assuming ratios of 300:1 for oral to IT morphine and 10:1 for oral methadone to morphine). This conversion could be subject to changes as individual conversion ratios for opioids differ and conversion ratios for intrathecal as low as 12:1 have been reported [20].

\section{Mode of delivery}

Intrathecal medications are delivered via an implanted catheter from a pump that is either external or implanted. Implanted devices are more appropriate in a patient with a life expectancy of 1-2 years [3]. ABN had a tunneled intrathecal catheter with a percutaneous port, which is the system used in most of the patients in a local audit [21]. This technique is considered less invasive and suitable for patients with limited life expectancy. She also was able to use patient controlled intrathecal analgesia (PCIA) with her intrathecal infusion.
Intrathecal infusions use a lower dose and volume compared to epidural infusions, hence there can be longer intervals between pump refills [3]. This approach is useful for managing the palliative care patient as the logistics of pump refills often need to be considered in view of the patient moving between care settings. ABN was initially planned for transfer to inpatient hospice and that necessitated discussion with the hospice team regarding management of her CADD pump.

\section{Intrathecal medications}

Morphine is the only opioid approved by the Food and Drug Administration (FDA) for intrathecal delivery. However, other medications have been found to be safe and effective.

\section{(i) Local anaesthetics}

Local anaesthetics work by blocking sodium channels and inhibiting nociceptive signal transmission. Bupivacaine has synergism with morphine leading to reduced need for increase in intrathecal morphine doses [22]. However, a blinded randomized controlled trial found that the addition of bupivacaine to intrathecal opioid did not lead to improved analgesia [23].

\section{(ii) Alpha-2 adrenoceptor agonist}

Clonidine is an alpha- 2 adrenoceptor agonist. It acts synergistically with opioids and has been shown to be effective in cancer pain [24,25]. In a local audit, clonidine was added for 3 out of 29 patients on intrathecal analgesia [21].

Other drugs that that have been used intrathecally include ziconotide, baclofen and hydromorphone. However, a systematic review of spinal opioids state that only bupivacaine or clonidine can be justified in combination therapy with morphine [26].

\section{Efficacy}

The use of epidural and intrathecal analgesia in selected patients is supported by evidence from a randomized controlled trial [27] and several uncontrolled trials [28].

In a Cochrane review assessing the effectiveness of neuraxial opioid therapy (intracerebroventricular, epidural or subarachnoid/ intrathecal), where data was mostly from uncontrolled studies, intrathecal therapy led to $62 \%$ of patients achieving excellent pain relief [29]. A randomized clinical trial of comprehensive medical management (CMM) versus intraspinal drug delivery systems (IDDS) showed pain relief of $57.9 \%$ with IDDS compared to $33.3 \%$ with CMM

Table 3. Differences between Convention and Epidural/Intraspinal Delivery Routes for Analgesics

\begin{tabular}{|c|c|c|}
\hline Drug Class & Conventional & Epidural/Intraspinal \\
\hline Opioids & Available, limited by side effects & Many available \\
\hline Alpha-adrenergic agonists & $\begin{array}{c}\text { Dexmedetomidine (Costly, requires intravenous } \\
\text { administration) }\end{array}$ & $\begin{array}{c}\text { Mexiletine } \\
\text { Effective and inexpensive }\end{array}$ \\
\hline Local anaesthetics & Limited or no efficacy in randomized trials & Bupivacaine and lidocaine-type drugs commonly used \\
\hline Calcium channel blockers & Oral drugs ineffective for pain relief & Ziconotide \\
\hline Muscle relaxants & Available, limited by side effects and efficacy & Intrathecal baclofen as third line option \\
\hline
\end{tabular}

Adapted from: Bobb \& Smith, Evidence-based Practice of Palliative Med Chapter 18

Table 4. Conversion ratios for morphine

\begin{tabular}{|c|c|c|c|c|}
\hline & Oral dose & Intravenous dose & Epidural dose \\
\hline Morphine $(\mathrm{mg})$ & 300 & 100 & 10 \\
\hline
\end{tabular}

Adapted from: Bobb \& Smith, Evidence-based Practice of Palliative Med Chapter 18 
[27] and better drug toxicity scores. However, there were significant flaws in this study's methodologies and results analysis.

Oral and subcutaneous morphine was found to have similar efficacy to epidural morphine. Advantages in terms of efficacy and dose reduction were seen with the addition of local anaesthetics [22], clonidine or ketamine to epidural or intrathecal infusions.

Following a review of the evidence, the EAPC thus issued a weak recommendation for spinal (epidural or intrathecal) opioids in combination with local anaesthetics or clonidine for patients with inadequate response to analgesia or intolerable side effects despite optimal use of analgesia [30]. Locally, an audit of 29 patients done in a tertiary hospital showed significant pain reduction following intrathecal analgesia [21], with average pain scores reduced from 7.7 to 2.2 .

\section{Patient selection}

Patient assessment and selection is important in achieving good outcomes for interventional analgesia. Following comprehensive pain assessment and definition of the pain syndrome, the appropriate intervention can then be planned. Understanding the patient's psychological, social and emotional issues is important as it may affect outcomes [31]. The patient's expectations regarding treatment end points and achievable symptom control have to be addressed [3] .

\section{Perception of intrathecal analgesia}

For many patients, intervention is perceived as a last resort measure and they may have endured considerable distress before finally agreeing to intervention. In ABN's case, she had previously declined intervention once. In a retrospective study of bereaved carers regarding intrathecal analgesia, they described that intrathecal analgesia was used in desperate situations. They felt that quality of life achieved outweighed inconveniences and side effects of therapy and some suggested earlier use [32]. Carers expressed the importance of having an additional option when conventional systemic analgesia was exhausted. However, carers who had lodged complaints about treatment or care were excluded from the study.

Physician perception also affects whether patients receive interventional management. There is a role for increased collaboration between specialist palliative and pain physicians in order to achieve better patient outcomes [33]. The barriers to increased integration are summarised in Table 5 below.

Table 5. Barriers to links between specialist pain management and palliative medicine Short survival of patients following referral to palliative care services Funding of the service

Time on the part of the pain specialists for proper assessment and discussion

Facilities for performing interventions may not be easily accessible

Complexity/lack of real understanding

Staff training in the management of pumps and catheters

Pharmacy issues: Procurement of solutions/availability of preservative-free opioid, lack of sterile facilities for making up infusions

Cost of implanted devices

Care issues for neuraxial infusions at home

Lack of availability of pain specialists out-of-hours

Palliative care doctor unaware of potential benefits/unsure how to access expertise

Pain doctor may not be adequately trained in the management of cancer pain/selection of an appropriate technique

\section{Failure of intrathecal analgesia}

Intrathecal analgesia is ineffective in about one-third of patients [34]. Neuropathic pain, incident pain and mucocutaneous ulcer pain are predictors for poor response [35]. Presence of other sources of distress leading to total pain are also factors in the failure of intrathecal analgesia.

In a case report on a patient who had poor response to systemic and intrathecal analgesia, an interdisciplinary palliative care intervention resulted in weaning off of intrathecal analgesia and significant reduction in systemic opioid dose [36]. In ABN's case, following a multidisciplinary session, she was more comfortable the following day. However, she subsequently developed new symptoms and deteriorated, hence further assessment of her psychological coping was not possible.

\section{Conclusion}

ABN had complex pain from DLBCL and psychosocial distress. She had been supported constantly for psychosocial issues and managed to achieve some gains such as reconciliation with her son. Despite this, her pain had steadily escalated with disease progression and she had multiple side effects with medications. She deteriorated shortly after insertion of her IT catheter while her dose was still being titrated.

Intrathecal analgesia may have been more useful for $\mathrm{ABN}$ if she had allowed for it earlier with a clear understanding of the risks, benefits and possible outcomes in terms of symptom control. Other considerations include greater collaboration with the pain team and medical social workers for cases with complex pain and more consistency in having an interpreter for patients with language barriers.

\section{References}

1. Van den Beuken-van Everdingen MHJ, HochsteABNch LMJ, Joosten EAJ, TjanHeijnen VCG, Janssen DjA (2016) Update on Prevalence of Pain in Patients with Cancer: Systematic Review and Meta-Analysis. J Pain Symptom Manage 51: 10701090.e9. [Crossref]

2. Zech DF, Grond S, Lynch J, Hertel D, Lehmann KA (1995) Validation of World Health Organization Guidelines for cancer pain relief: a 10-year prospective study. Pain 63: 65-76. [Crossref]

3. Tay W and Ho KY (2009) The role of interventional therapies in cancer pain management. Ann Acad Med Singapore 38: 989-997. [Crossref]

4. Fainsinger RL and Nekolaichuk CL (2008) A 'TNM' classification system for cancer pain: the Edmonton Classification System for Cancer Pain (ECS-CP). Support Care Cancer 16: 547-555. [Crossref]

5. https://www.iasp-pain.org/Education/Content.aspx?ItemNumber=1698\&navItemNum ber $=576$.

6. Bruera E (1995) A prospective multicenter assessment of the Edmonton staging system for cancer pain. J Pain Symptom Manage 10: 348-355. [Crossref]

7. Hjermstad MJ, Fainsinger R, Kaasa S, European Palliative Care Research Collaborative (EPCRC) (2009) Assessment and classification of cancer pain. Curr Opin Support Palliat Care 3: 24-30. [Crossref]

8. Mercadante S (1997) Malignant bone pain: pathophysiology and treatment. Pain 69 1-18. [Crossref]

9. Yoneda T, Hiasa M, Nagata Y, Okui T, White FA (2015) Acidic microenvironment and bone pain in cancer-colonized bone. BoneKey Rep 4: 690. [Crossref]

10. Cherny NI (2005) How to deal with difficult pain problems (2005) Ann Oncol 16: ii79ii87. 
11. Finnerup NB (2015) Pharmacotherapy for neuropathic pain in adults: a systematic review and meta-analysis. Lancet Neurol 14: 162-173. [Crossref]

12. Gilron I, Bailey JM, Tu D, Holden RR, Weaver DF, et al. (2005) Morphine, gabapentin, or their combination for neuropathic pain. $N$ Engl J Med 352: 1324-1334. [Crossref]

13. Gilron I, Bailey JM, Tu D, Holden RR, Jackson AC, et al. (2009) Nortriptyline and gabapentin, alone and in combination for neuropathic pain: a double-blind, randomised controlled crossover trial. Lancet 374: 1252-1261. [Crossref]

14. Nicholson AB, Watson GR, Derry S, Wiffen PJ (2017) Methadone for cancer pain Cochrane Database Syst Rev 2: CD003971.

15. Mercadante S (2001) Switching from morphine to methadone to improve analgesia and tolerability in cancer patients: a prospective study. J Clin Oncol 19: 2898-2904. [Crossref]

16. Mercadante S and Bruera E (2018) Methadone as a First-Line Opioid in Cancer Pain Management: A Systematic Review. J Pain Symptom Manage 55: 998-1003. [Crossref]

17. Stearns L (2005) Intrathecal drug delivery for the management of cancer pain: a multidisciplinary consensus of best clinical practices. J Support Oncol 3: 399-408. [Crossref]

18. Coyne PJ, Smith T, Laird J, Hansen LA, Drake D (2005) Effectively starting and titrating intrathecal analgesic therapy in patients with refractory cancer pain. Clin J Oncol Nurs 9: 581-583. [Crossref]

19. Krames ES (1996) Intraspinal opioid therapy for chronic nonmalignant pain: current practice and clinical guidelines. J Pain Symptom Manage 11: 333-352. [Crossref]

20. Sylvester RK, Lindsay SM, Schauer C (2004) The conversion challenge: from intrathecal to oral morphine. Am J Hosp Palliat Care 21: 143-147. [Crossref]

21. Pasutharnchat K, Tan KH, Abdul Hadi M, Ho KY (2009) Intrathecal analgesia in patients with cancer pain--an audit in a tertiary institution. Ann Acad Med Singapore 38: 943-946. [Crossref]

22. Van Dongen RT, Crul BJ, Van Egmond J (1999) Intrathecal coadministration of bupivacaine diminishes morphine dose progression during long-term intrathecal infusion in cancer patients. Clin J Pain 15: 166-172. [Crossref]

23. Mironer YE, Haasis JC, Chapple I, Brown C, Satterthwaite JR (2003) Efficacy and Safety of Intrathecal Opioid/Bupivacaine Mixture in Chronic Nonmalignant Pain: A Double Blind, Randomized, Crossover, Multicenter Study by the National Forum of Independent Pain Clinicians (NFIPC). Neuromodulation 5: 208-213. [Crossref]
24. Eisenach JC, DuPen S, Dubois M, Miguel R, Allin D (1995) Epidural clonidine analgesia for intractable cancer pain. The Epidural Clonidine Study Group. Pain 61 : 391-399. [Crossref]

25. Coombs DW, Saunders RL, Lachance D, Savage S, Ragnarsson TS, et al. (1985) Intrathecal morphine tolerance: use of intrathecal clonidine, DADLE, and intraventricular morphine. Anesthesiology 62: 358-363. [Crossref]

26. Kurita GP, Kaasa S, Sjøgren P, European Palliative Care Research Collaborative (EPCRC) (2011) Spinal opioids in adult patients with cancer pain: a systematic review: a European Palliative Care Research Collaborative (EPCRC) opioid guidelines project Palliat Med 25: 560-577. [Crossref]

27. Smith TJ (2002) Randomized clinical trial of an implantable drug delivery system compared with comprehensive medical management for refractory cancer pain: impact on pain, drug-related toxicity, and survival. J Clin Oncol 20: 4040-4049. [Crossref]

28. Hassenbusch SJ, Stanton-Hicks MD, Soukup J, Covington EC, Boland MB (1991) Sufentanil citrate and morphine/bupivacaine as alternative agents in chronic epidural infusions for intractable non-cancer pain. Neurosurgery 29: 76-81. [Crossref]

29. Ballantyne JC and Carwood CM (2005) Comparative efficacy of epidural, subarachnoid, and intracerebroventricular opioids in patients with pain due to cancer. Cochrane Database Syst Rev 1: CD005178. [Crossref]

30. Caraceni A (2012) Use of opioid analgesics in the treatment of cancer pain: evidencebased recommendations from the EAPC. Lancet Oncol 13: e58-68. [Crossref]

31. Manchikanti L, Fellows B, Singh V (2002) Understanding psychological aspects of chronic pain in interventional pain management. Pain Physician 5: 57-82. [Crossref]

32. Patel N (2018) Was it worth it?' Intrathecal analgesia for cancer pain: A qualitative study exploring the views of family carers. Palliat Med 32: 287-293. [Crossref]

33. Brien TO and Kane CM (2014) Pain services and palliative medicine - an integrated approach to pain management in the cancer patient. Br J Pain 8: 163-171. [Crossref]

34. Baker L, Lee M, Regnard C, Crack L, Callin S, et al. (2004) Evolving spinal analgesia practice in palliative care. Palliat Med 18: 507-515.

35. Samuelsson H, Malmberg F, Eriksson M, Hedner T (1995) Outcomes of epidural morphine treatment in cancer pain: nine years of clinical experience. J Pain Symptom Manage 10: 105-112. [Crossref]

36. Reddy A, Hui D, Bruera E (2012) A Successful Palliative Care Intervention for Cancer Pain Refractory to Intrathecal Analgesia. J Pain Symptom Manage 44: 124-130. [Crossref]

Copyright: ( 2019 Natalie WL. This is an open-access article distributed under the terms of the Creative Commons Attribution License, which permits unrestricted use, distribution, and reproduction in any medium, provided the original author and source are credited. 